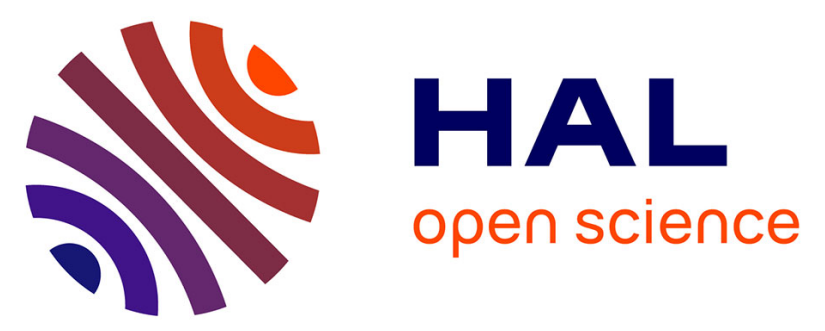

\title{
The effects of incident electron current density and temperature on the total electron emission yield of polycrystalline CVD diamond
}

Mohamed Belhaj, T Tondu, T , V Inguimbert, Pierre Barroy, François Silva, Alix Gicquel

\section{To cite this version:}

Mohamed Belhaj, T Tondu, T , V Inguimbert, Pierre Barroy, et al.. The effects of incident electron current density and temperature on the total electron emission yield of polycrystalline CVD diamond. Journal of Physics D: Applied Physics, 2010, 43 (13), pp.135303. 10.1088/0022-3727/43/13/135303 . hal-00569568

\section{HAL Id: hal-00569568 \\ https://hal.science/hal-00569568}

Submitted on 25 Feb 2011

HAL is a multi-disciplinary open access archive for the deposit and dissemination of scientific research documents, whether they are published or not. The documents may come from teaching and research institutions in France or abroad, or from public or private research centers.
L'archive ouverte pluridisciplinaire HAL, est destinée au dépôt et à la diffusion de documents scientifiques de niveau recherche, publiés ou non, émanant des établissements d'enseignement et de recherche français ou étrangers, des laboratoires publics ou privés. 


\title{
Effects of the incident electron current density and the temperature on the total electron emission yield of polycrystalline CVD-diamond
}

\author{
M Belhaj ${ }^{1,2,4}$, T Tondu ${ }^{1}$ T, V Inguimbert ${ }^{1}$, Pierre Barroy ${ }^{3}$, François Silva ${ }^{3}$, Alix \\ Gicquel $^{3}$
}

${ }^{1}$ ONERA/DESP 2, Avenue Edouard Belin, 31400 Toulouse Cédex, France

2 STAE, 5 rue Paulin Talabot, BP 1301, 31106 Cédex 1, Toulouse, France

${ }^{3}$ LIMHP Université Paris 13 CNRS Institut Galilée 99 avenue Jean-Baptiste Clément 93430

Villetaneuse FRANCE

E-mail: Mohamed.Belhaj@onera.fr

${ }^{4}$ Author to whom any correspondence should be addressed

Mohamed.Belhaj@onera.fr

PACS numbers 61.80. Fe; 61.82 Ms; $68.49 \mathrm{Jk}$

Submitted to Journal of Physics D: Applied Physics 


\begin{abstract}
:
Effects of the temperature and the incident electron current density on the total electron emission yield (TEEY) of polycrystalline diamond deposited by chemical vapor deposition technique (CVD) were investigated at low electron beam fluence. It was found that the TEEY reversibly increases with the temperature and reversibly decreases with the current density. This behavior is explained on the basis of a dynamic completion between the holes accumulation which (positive space charge) that internally diminish the secondary electron (SE) emission and the thermally activated conductivity that tends to reduce the space charge formation.
\end{abstract}

\title{
I. Introduction
}

Due to low or even negative electron affinity and to wide energy bandgap, diamond exhibits generally a relatively high total electron emission yield (TEEY). The TEEY is the number of emitted electrons (secondary and backscattered) to the incident electrons number. Depends on its surface termination [1], doping level and nature [2], thickness [3], surface roughness [4] temperature and electron fluence (efluence) [5], etc, the reported yield maximum varies from more than 80 in monocristal (100) with hydrogenated or cesiated surface [6] to about 10 in polycrystalline diamond films deposited by chemical vapor deposition technique (CVD). Owing to its high TEEY diamond emerges as a very interesting material for electron multiplication and particles detector [4,7]. Recently, Stacey and al [5], have investigated the effect of the moderate sample heating in conjunction with the effect of e-fluence on the TEEY of CVDdiamond with hydrogenated surface. They established that under continuous e-irradiation, both electrons stimulate desorption (ESD) of hydrogen and charge trapping play a major role on secondary electron (SE) emission process. In this paper, we report results on the effects of the temperature and of the incident current density on TEEY of a polycrystalline H-terminated CVD diamond layer. In order to prevent a possible ESD and electron induced contamination phenomena, very low e-fluence were used $\left(10^{6} \mathrm{e} / \mathrm{cm}^{2}\right.$ to $10^{9} \mathrm{e} / \mathrm{cm}^{2}$ ). We have found that increasing the temperature and/or reducing the current density result in a significant enhancement of the TEEY. These results are explained in terms of a dynamic competition between the formation of a positive space charge (holes accumulation) that internally reduces the SE emission [8-10] and the thermally activated conduction of diamond [11,12] that tends to reduce the space charge formation.

\section{Experimental}

\section{A. Samples}

The polycrystalline H-terminated CVD diamond layer has been grown in a silica bell jar low pressure chamber where the gas mixture was activated by a microwave electric field (see figure 1). 
Conventional experimental conditions were set at: $2 \mathrm{~kW}, 100$ mbar, $2.5 \% \mathrm{CH} 4$, substrate temperature $890{ }^{\circ} \mathrm{C}$. The $21 \mu \mathrm{m}$ thick layer microstructure and purity have been determined by respectively scanning electron microscopy (figure 2).

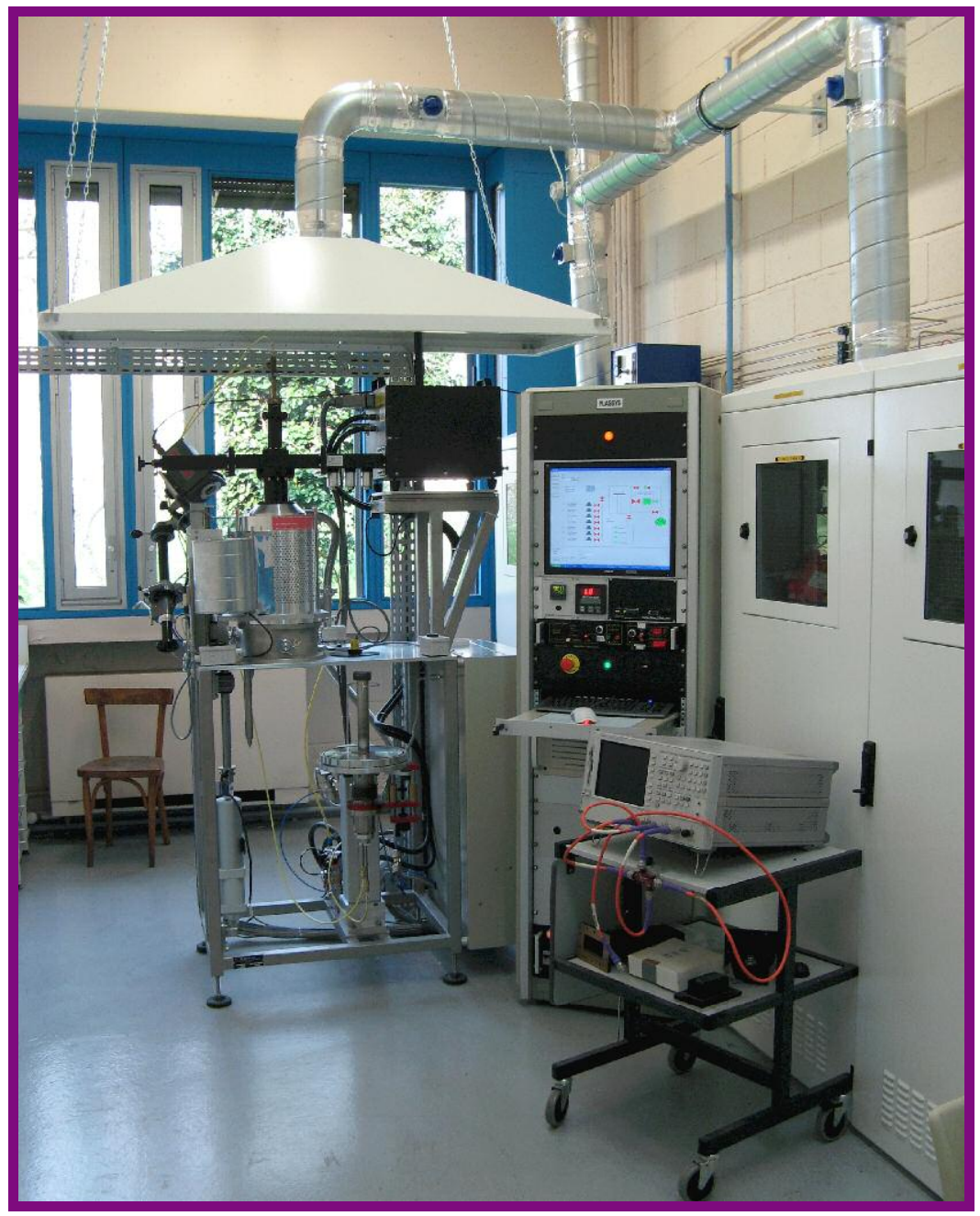

Figure 1 : experimental set up for diamond growth. 


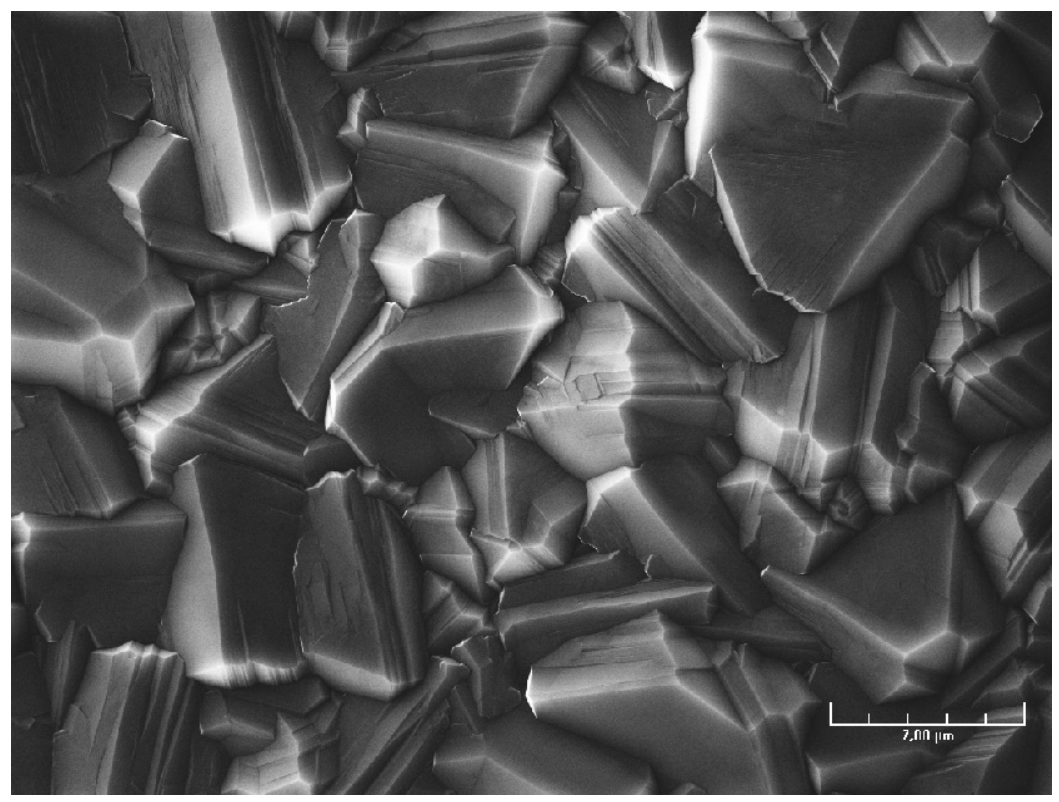

Figure 2: Scanning electron micrography of the polycrystalline diamond layer used for the study.

\section{B. Electron emission yield measurement}

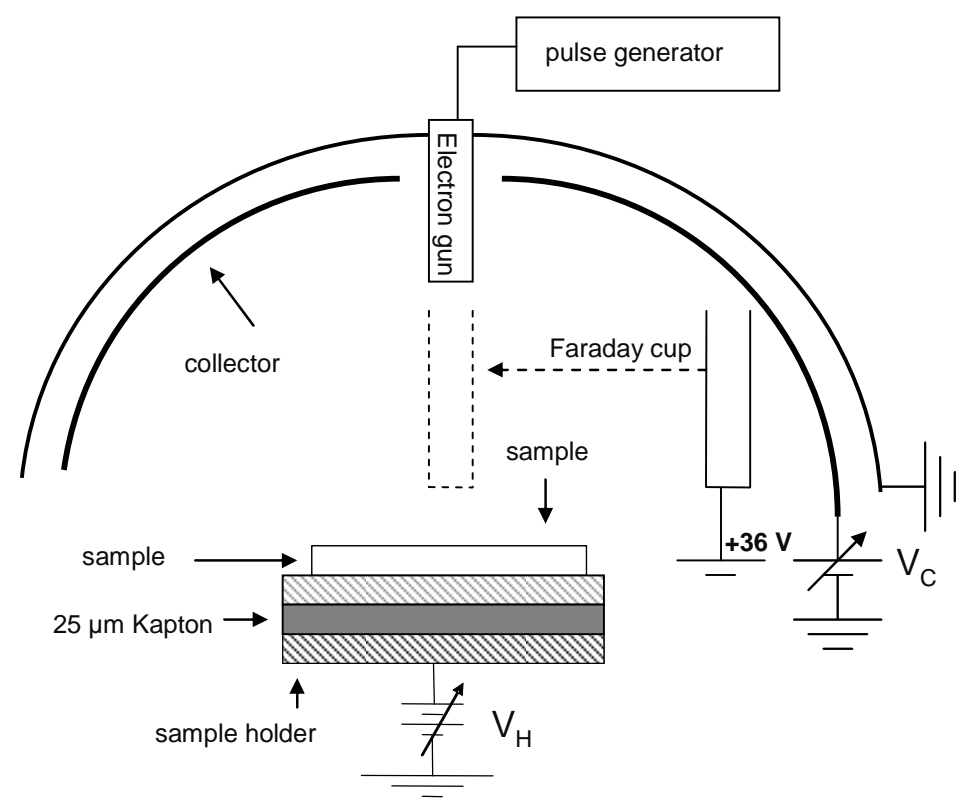

Figure 3. Experimental setup

The experimental setup is shown in figure 3. Cryogenic pump associated to oil-free molecular-diaphragm pumps allow the system to be maintained at vacuum level down to $510^{-8}$ Torr. A hemispherical electroncollecting electrode (collector) faces the sample surface. The sample holder and the collector can be independently biased to choose the desired potential. Sample current is monitored using $350 \mathrm{Mhz}$ TDS5034B oscilloscope connected to a Femto-DHPCA-100 high speed and a low noise current amplifier. 
The electron beam incidence is set normal to the sample surface. ELG2 Kimball instrument electron gun with a $\mu$ s electron beam pulsing capacities was used as the electron source. The incident charge per pulse, $\Delta Q_{i}$ is measured using a Faraday cup connected to oscilloscope throughout a second DHPCA-100 current amplifier. The total electron yield can be obtained from:

$$
\sigma=\frac{\Delta Q_{i}-\Delta Q_{S}}{\Delta Q_{i}}
$$

$\Delta Q_{S}$ is the flowed charge from the sample to the ground. $\Delta Q_{i}$ was varied in this experiment between $310^{-13}$ $\mathrm{C}\left(2.410^{6} \mathrm{e} / \mathrm{cm}^{2}\right)$ and $510^{-11} \mathrm{C}\left(410^{8} \mathrm{e} / \mathrm{cm}^{2}\right)$. The e-irradiation was performed at fixed spot diameter of $\sim 5$ $\mathrm{mm}$ and at fixed pulse duration of $50 \mu \mathrm{s}$. The e-fluence was varied by varying the beam current from $5 \mathrm{nA}$ to $320 \mathrm{nA}$. Due to the fact that $\sigma>1$ in the investigated energy range (30 eV-2 keV), surface positive charging is expected, which could attract back the emitted electrons. Assuming that $\sigma=10$ and that all generated holes due to the SE emission are trapped in the sample (worst case), the induced positive surface potential $V s$ should be at the maximum $4 \mathrm{~V}$. For the last calculation the relative dielectric permittivity of the sample, $\varepsilon_{r}$, was assumed to be 5.7. A positive $V s$ (even of few tens of $\mathrm{mV}$ ) leads to a substantial SE emission drop [7, 13, 14]. This effect (external charging effect) on the TEEY is illustrated on studied sample in figure 4 , where the $\sigma$ dependence to the sample holder bias, $V_{H}$ (the S-curve) is plotted. The TEEY is nearly constant bellow $V_{H}=-3 \mathrm{~V}$ and starts to sharply decreases when $V_{H}$ is positively increased. To circumvent the SE blocking due to the work function difference between the electron gun cathode and the sample holder and due to possible charging effect, the sample holder was set to a negative value with respect to its surrounding $\left(V_{H}=-18 \mathrm{~V}\right)$.

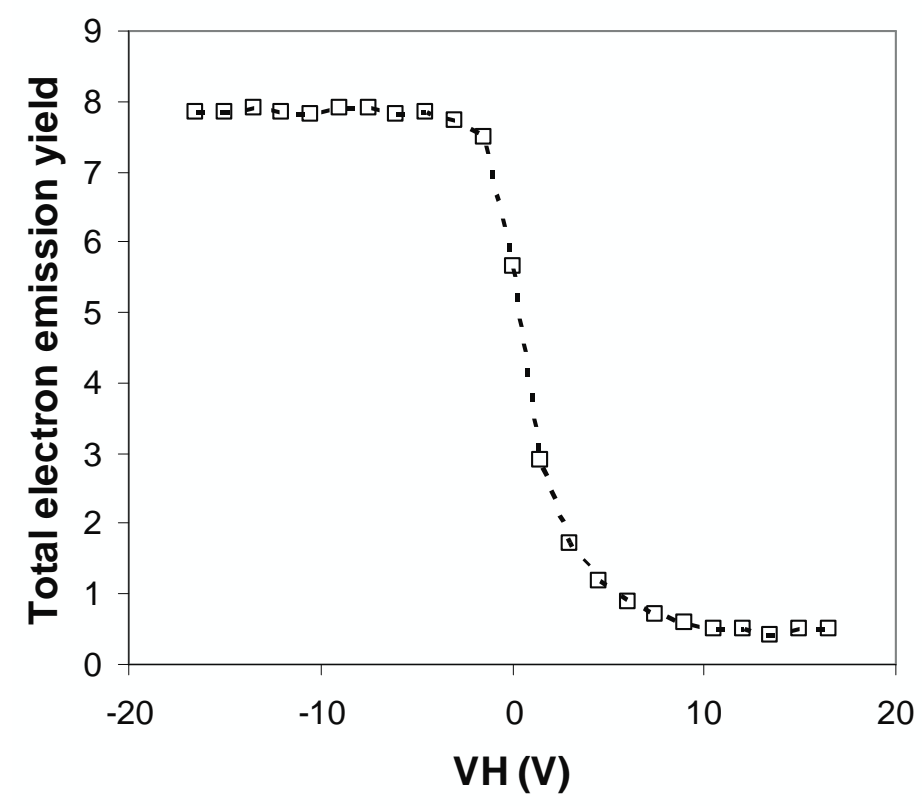

Figure 4: TEEY as function of the sample holder bias, $\mathrm{V}_{\mathrm{H}}$ at $1 \mathrm{keV}$ primary beam energy. $\mathrm{T}=25^{\circ} \mathrm{C}, J_{0} \approx 30$ $\mathrm{nA} / \mathrm{cm}^{2}, \mathrm{~V}_{\mathrm{C}}=0 \mathrm{~V}$. 


\section{Results}

\section{A. Effect of the current density}

The TEEY curves measured using low $\left(\sim 30 \mathrm{nA} / \mathrm{cm}^{2}\right)$, medium $\left(\sim 130 \mathrm{nA} / \mathrm{cm}^{2}\right)$ and high $\left(\sim 310 \mathrm{nA} / \mathrm{cm}^{2}\right)$ incident current density, $j_{0}$ are shown in figure $5 \mathrm{a}$. An overall decrease of the electron emission yield is observed when the electron fluence is increased. Note that the energy at which occurs the maximum of the TEEY is comparable to that reported previously by several groups on CVD-polycrystalline diamond [15, 16]. The maximum electron emission yield, $\sigma_{\max }$ at incident electron energy, $E_{0}$ of $1 \mathrm{keV}$ as the function of the incident current density is plotted in figure 5b. $\sigma_{\max }$ decreases rapidly from $\sim 12$ at $j_{0}=5 \mathrm{nA} / \mathrm{cm}^{2}$ to $\sim 6$ at $j_{0}=310 \mathrm{nA} / \mathrm{cm}^{2}$ and thereafter remains roughly constant. It should be noticed that $\sigma_{\max }$ variation with the incident current density is reversible.

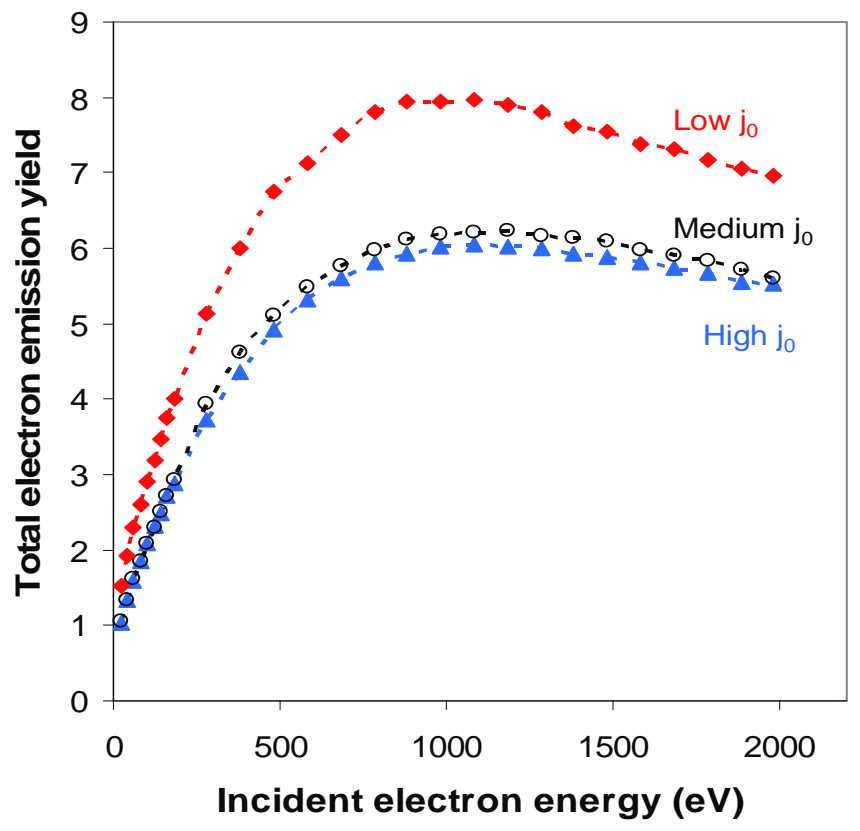

(a) 


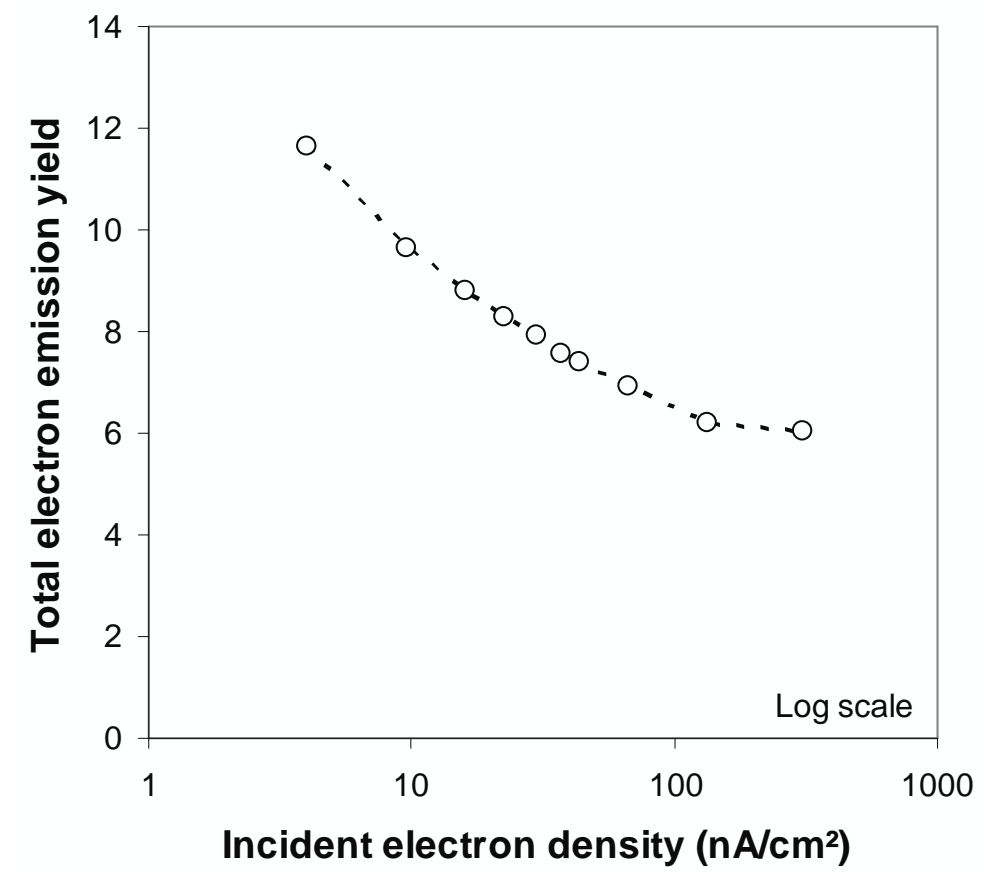

(b)

Figure 5: (a) TEEY as the function of the primary electron energy measured using $\left(\sim 30 \mathrm{nA} / \mathrm{cm}^{2}\right)$ medium $\left(\sim 130 \mathrm{nA} / \mathrm{cm}^{2}\right)$ and high $\left(\sim 310 \mathrm{nA} / \mathrm{cm}^{2}\right)$ current density. (b) Maximum of the TEEY (at $E_{0}=1 \mathrm{keV}$ ) as the function of the incident electron current density. $V_{H}=-18 \mathrm{~V}$ and $T=25^{\circ} \mathrm{C}$.

\section{B. Effect of the temperature}

Figure 6 and figure 7 show the influence of the temperature on the electron emission yield. When low current density is used $\left(30 \mathrm{nA} / \mathrm{cm}^{2}\right)$, a significant rise of the TEEY is observed when the temperature is increased from $25^{\circ} \mathrm{C}$ to $90^{\circ} \mathrm{C}$ (Figure 6). When high current density $\left(310 \mathrm{nA} / \mathrm{cm}^{2}\right)$ is used, only a slight increase of the TEEY is observed. Note that the change on $\sigma$ as function of the temperature is also reversible. 


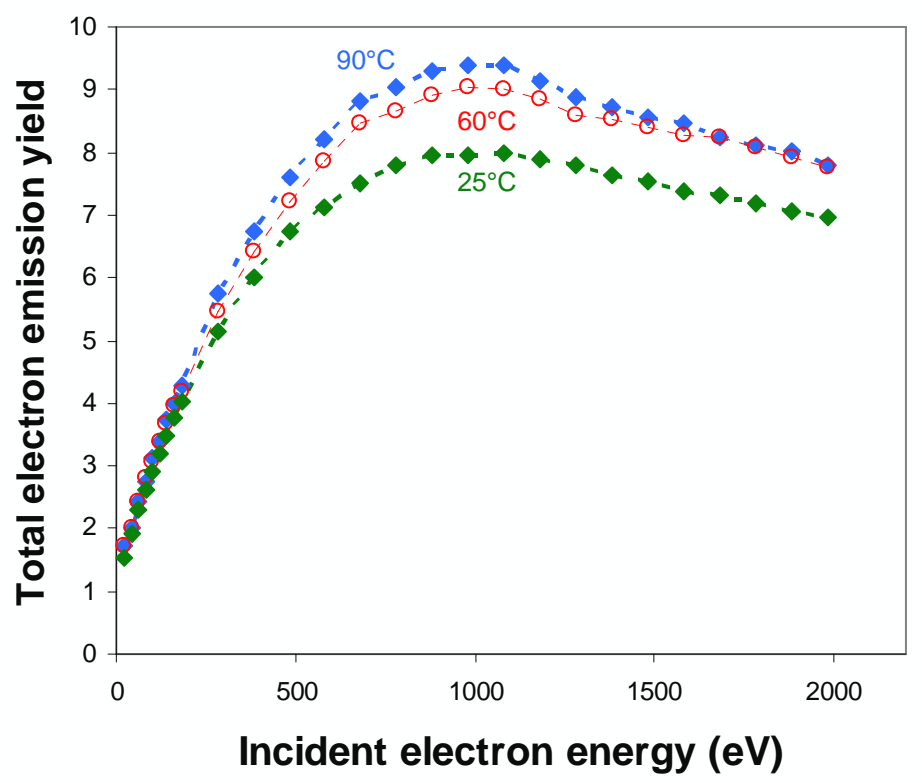

Figure 6: TEEY as the function of the incident electron energy .T $=25^{\circ} \mathrm{C}, 60^{\circ} \mathrm{C}$ and $90^{\circ} \mathrm{C} . J_{0}=30 \mathrm{nA} / \mathrm{cm}^{2}$.

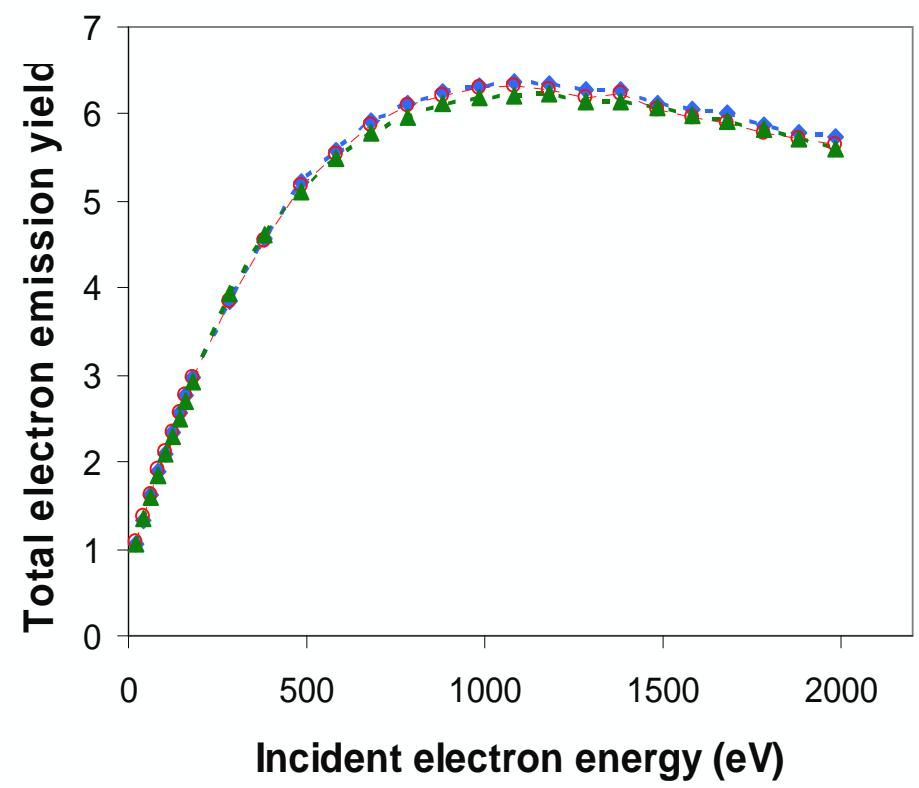

Figure 7: TEEY as the function of the incident electron energy $. \mathrm{T}=25^{\circ} \mathrm{C}, 60^{\circ} \mathrm{C}$ and $90^{\circ} \mathrm{C} . J_{0}=310 \mathrm{nA} / \mathrm{cm}^{2}$.

\section{Discussion}

In their recent study, Stacey et al [5] have shown that the decay of the TEEY of CVD-hydrogenated diamond as the function of the e-fluence is reduced or even canceled when the temperature is moderately increased. This observed decay was associated to the electron stimulate desorption of hydrogen (ESD) that 
induces an increase of the electron affinity. Indeed, the yield of the ESD of hydrogen declines when the temperature increases [17]. In contrast to Stacey et al [5] experiments where continuous irradiation is used, in our experiments, the incident e-fluence was kept very low thanks to the use of short duration electron pulses. All observed variations of TEEY in this work are fully reversible without requiring any specific surface treatment (plasma exposure or heat treatment). This suggests that the used total e-fluence for the present TEEY measurements is most probably not sufficient to induce any significant surface modification such as ESD or electron induced contaminant deposition $[18,19]$. We believe that our results can be explained in terms of a dynamic competition between on the one side, the positive charging resulting from the SE emission and on the other side, the temperature sensitive conductivity of diamond that tends to prevent the charge accumulation thanks to easier flow of charge carriers between the diamond surface and the substrate. It was established that the conductivity, $\gamma$, of the CVD-diamond is mainly governed by hopping mechanism [10]. $\gamma$ can be expressed as:

$\gamma(T)=\sigma_{0} \exp \left[-E_{a} / k T\right]$

where $E_{a}$ is the activation energy of the hopping process. $E_{a}$ is highly dependent on sample growth conditions. The reported values in the literature are in $0.2 \mathrm{eV}-0.65 \mathrm{eV}$ range $[10,11]$. Accordingly, the elevation of the temperature from $25^{\circ} \mathrm{C}$ to $90^{\circ} \mathrm{C}$ enhances the conductivity by a factor ranging from 4 to 50 . Consequently, when the temperature is increased, charge carrier flows more easily between the Si substrate and the diamond surface; the rate of the space charge formation is then reduced. Charging may affects the SE emission by two distinct ways:

- internally, by acting on the SE transport and escape into the vacuum and

- externally, by attracting back the emitted SE.

A comprehensive description of the influence of charging on the TEEY can be found for instance in Cazaux works [7,20,21]. In order to discriminate between internal and external effects of charging, we have investigated the effects of the temperature and current density change on the S-curves (TEEY dependence to the sample holder bias $\mathrm{V}_{\mathrm{H}}$ ). The results are shown in figure $8 \mathrm{a}$. The incident electron energy was set at $1 \mathrm{keV}$. It is interesting to notice that TEEY varies only in magnitude: the three normalized S-curves overlap perfectly (figure $8 \mathrm{~b}$ ). Positive surface potential variation, $\Delta V_{S}$ with respect to the grounded collector (negative $\Delta V_{S}$ ) should induce an overall shift of the S-curves to lower $V_{H}$ (higher $V_{H}$ ). An example of the effect of external charging on the S-curve is illustrated in figure 8c: when a positive surface potential $\Delta V_{S}$ (negative surface potential $\left(\Delta V_{S}\right)$ is induced by biasing negatively (positively) the collector, an overall shift of the S-curve to the left (right) is observed. This shift was not observed in figure $8 \mathrm{~b}$. This suggests that the TEEY variations shown in figures 3 and 4 are not related to an external effect of charging, but rather are linked to internal effects. 


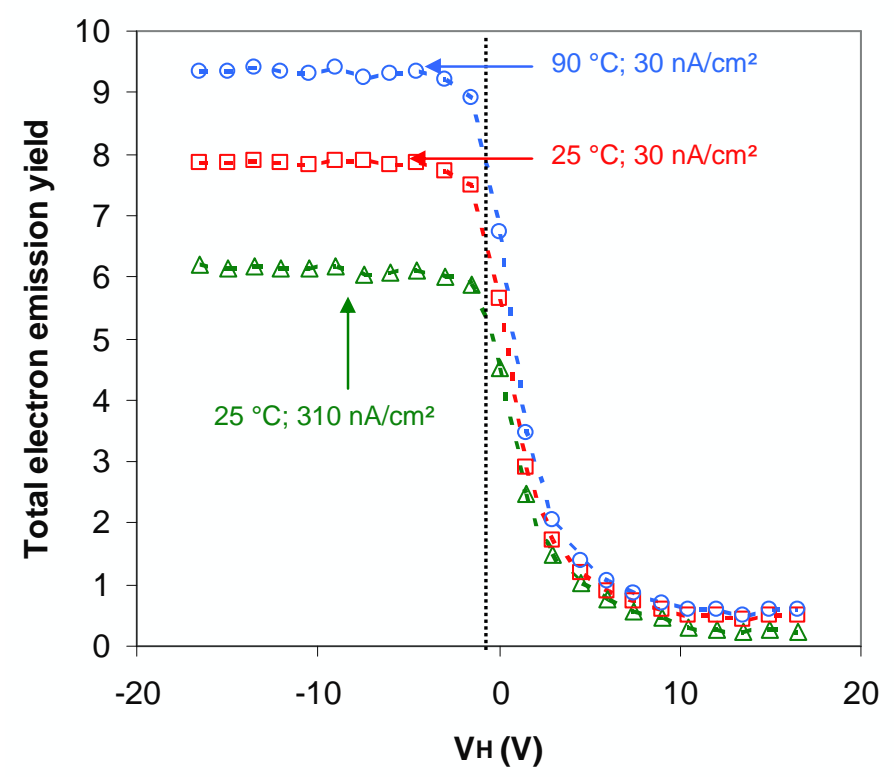

(a)

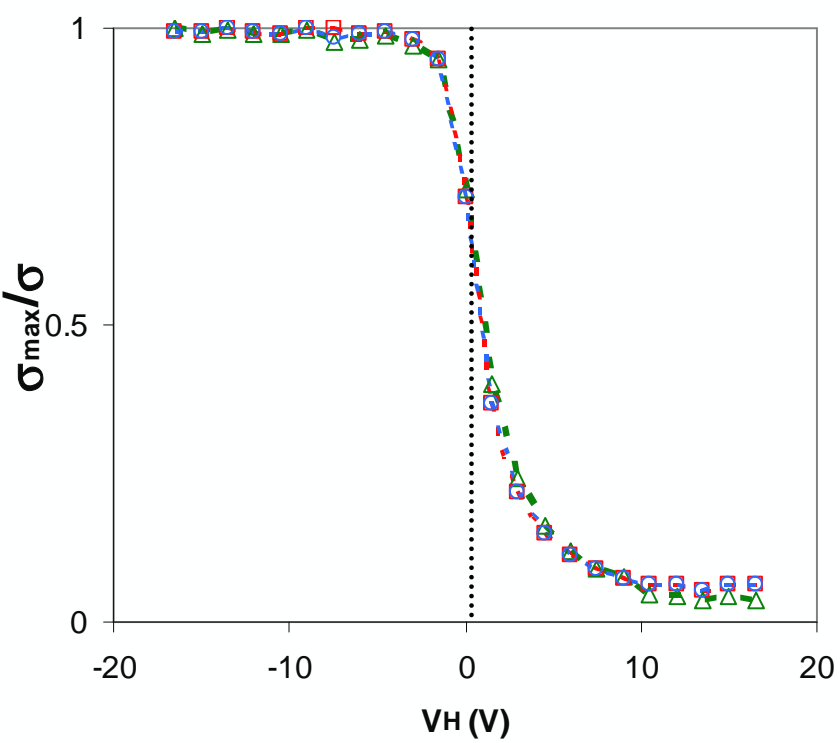

(b) 


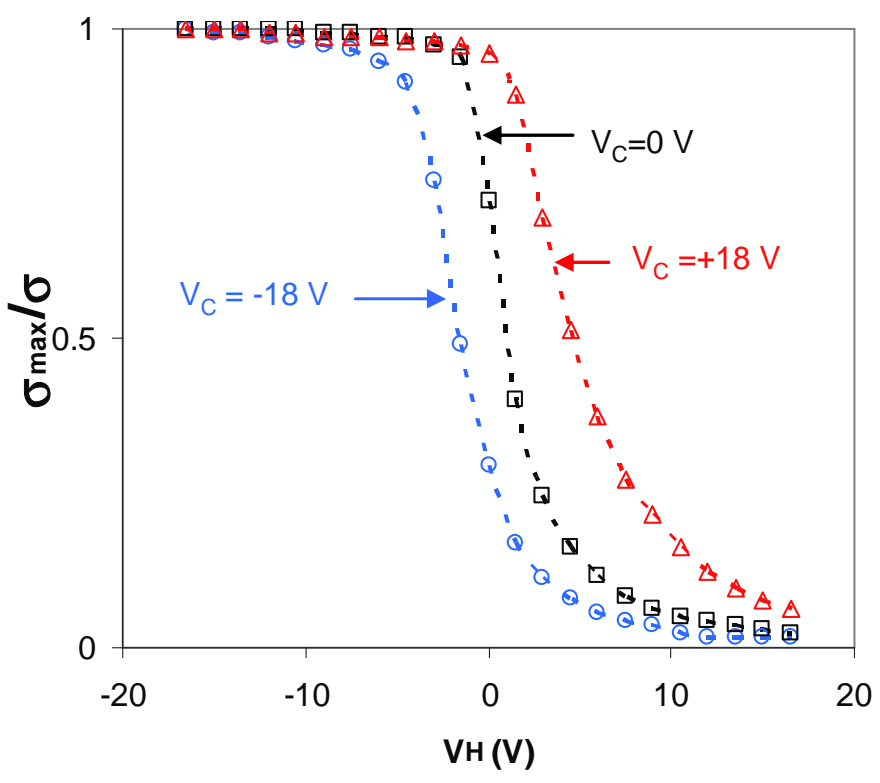

(c)

Figure 8: (a) TEEY at $1 \mathrm{keV}$ as the function of the sample holder bias (S-curves) for 3 situations $\left(\mathrm{T}=25^{\circ} \mathrm{C}\right.$ and $\left.\mathrm{j}=30 \mathrm{nA} / \mathrm{cm}^{2}\right),\left(\mathrm{T}=25^{\circ} \mathrm{C}\right.$ and $\left.\mathrm{j}=310 \mathrm{nA} / \mathrm{cm}^{2}\right)$ and $\left(\mathrm{T}=90^{\circ} \mathrm{C}\right.$ and $\left.\mathrm{j}=30 \mathrm{nA} / \mathrm{cm}^{2}\right)$. (b) Normalized Scurves represented in (a). The measurements were performed at $V_{C}=O V$. (c) TEEY at $1 \mathrm{keV}$ and $\mathrm{j}=310$ $\mathrm{nA}$ as the function of the sample holder bias (S-curves) for 3 situations $V_{C}=0 \mathrm{~V}, V_{C}=-18 \mathrm{~V}$ and $V_{C}=+18 \mathrm{~V}$. $\mathrm{T}=25^{\circ} \mathrm{C}$

Two possible mechanisms that internally reduce the SE emission could explain our results.

(1) As the positive charge increases, the probability of recombination of low energy SE with holes increases and the mean free path of SE undergoing emission thereby decreases [8-10, 22]. The effect of such mechanism on the TEEY was recently observed by us on $\mathrm{MgO}$ [10].

(2) Holes accumulation induces an upward band bending at the vacuum/diamond interface, thus creating a blocking barrier for low energy SE undergoing emission. A detailed description of this phenomenon is given by Hoffman et al. [23,24]. This blocking mechanism is expected to be particularly effective in low or negative electric affinity materials (as the diamond) where a large number of the emitted SE are quasithermalized $[25,26]$

Based on the consideration developed above we attempt in the following to interpret our experimental results. The overall increase on the TEEY seen on the figure 6 when the temperature is increased is most likely due to the conductivity rises (see expression 2). The higher is the temperature and the easier is the flow of charge carriers (holes and electrons) between the Si substrate and the irradiated diamond surface. As the result, the increase of the temperature leads to the decrease of the hole density and 
therefore an enhancement of the TEEY. When the current density is high $\left(310 \mathrm{nA} / \mathrm{cm}^{2}\right)$, the increase of conductivity with temperature becomes insufficient to counterbalance the high rates of creation of holes (proportional to the current density). This probably explains why the effect of the temperature on the TEEY becomes much less important at high current density (figure 7).

\section{Conclusion}

We have investigated the conjugate effect of current density and temperature on the electron emission properties of a polycrystalline H-terminated CVD-diamond layer. We have found that increasing the temperature and/or decreasing the incident current density lead to an overall increase of the TEEY. The results are explained in terms of competition between on the one side the increase of positive charge density subsequent to the SE emission and on the other side temperature activated conductivity that tends to counterbalance the space charge formation thanks to easier flow of charge carriers between the substrate and the diamond.

\section{Acknowledgments}

This work was supported by the RTRA-STAE with the program PLASMAX and by the CNES.

\section{References}

[1] Krainsky I L, Asnin V M and Dayton jr J A 1997 Appl. Surf. Sci 111265.

[2] Shih A, Yater J, Hor C and Abrams R 1997 App. Surf. Sci 111251

[3] Michaelson S, Ternyak O, Akhvlediani R and Hoffman A 2008 Chem. Vap. Deposition 14212

[4] Ascarelli P, Cappelli E, Pinzari F, Rossi M C, Salvatori S, Merli P G and Migliori A 2001 J. Appl. Phys 689

[5] Stacey A, Prawar S, Rubanov S, Akhvlediani R and Michaelson Sh and Hoffman A 2009 J. Appl. Phys 106063715

[6] J. Yater J and Shih A 2000 J. Appl. Phys. 878103

[7] Mearini G T, I. L Krainsky I L, Wang Y X, Dayton jr J A, Ramesham R and Rose M F 1994 Thin. Solid Film 253151.

[8] Cazaux J 1999 J. Appl. Phys. 851137

[9] Melchinger A and Hofmann 1995 J. Appl. Phys. 786224

[10] Belhaj M, Tondu T and Inguimbert V 2009 J. Phys. D: Appl. Phys. 42145306

[11] Conte C, Rossi M C, Salvatori S, Spaziani F, Vitale G and Ascarelli P 2004 Diammond and Related Materials 13277

[12] Novikov N V, Nachalna T A, Ivakhnenko S A, Zanevsky O A, Belousov I S, Malogolovets V G, Podzyarei G Aand Romanko L A 2003 Diamond and Related Materials 121990

[13] Dennison J R, Thomson C D and Albertsen J, 2008 IEEE Trans. Plasma Sci. 362238

[14] J.J Scholtz J J, Schmitz R W A, Hendricks B H W and de Zwart S T 1997 App. Surf. Sci 111259 
[15] Trucchi D M, Scilletta C, Cappelli E, Meril P G, Zoffoli S, Mattei G and Ascarelli P 2006 Diamond and Related Materials 15817

[16] Ternyak O, Michaelson Sh, Akhvlediani R and Hoffman A 2006 Diamond and Related Materials 15 850

[17] Hoffman A, Ustaze S, Hadj Hamou M, Hedhlili M N, Le Coat Y, Azria R and Tronc M 2002 Phys. Rev. B 63245404

[18] Taniguchi Jun, Miyamoto Iwao, Ohno Naoto and Honda Satoshi 1997 Nucl. Instr. And Meth. In Phys. Res. B 121507

[19 Rau] E I 2008 Appl. Surf. Sci. 2542110

[20] Cazaux J 2008 Ultramicroscopy 1081645

[21] Cazaux J 2010 J. Electr. Spectr.and Related Phenomena 17658

[22] Hessel R and Gross B 1992 IEEE Trans. On Elec. Insul. 27831

[23] Hoffman A, Akhvleddiani R, Laikhtman A, Lafosse A, Guillotin J-P and Azria R 2004 J. Appl. Phys. 951895

[24] Hoffman A, Lafosse A, Azria R 2006 J. Phys. Rev. B 73085423

[25] Bozeman S P, Baumann P K, Ward B L, Powers M J, Cuomo J J, Nemanich R J and Dreifus D L 1996 Diamond and Related Materials 5802

[26] Yater J, Shih A and Abrams R 1997 Phys. Rev. B. 56 R4410. 